OPEN ACCESS

Edited by:

Angel Borja,

Tecnalia, Spain

Reviewed by:

Stelios Katsanevakis, University of the Aegean, Greece

Vanessa Stelzenmüller,

Thuenen Institute of Sea Fisheries,

Germany

${ }^{*}$ Correspondence: Samuli Korpinen samuli.korpinen@ymparisto.fi

Specialty section: This article was submitted to Marine Ecosystem Ecology, a section of the journal Frontiers in Marine Science

Received: 15 June 2016 Accepted: 12 August 2016

Published: 30 August 2016

Citation:

Korpinen S and Andersen JH (2016) A Global Review of Cumulative Pressure and Impact Assessments in Marine Environments. Front. Mar. Sci. 3:153. doi: 10.3389/fmars.2016.00153

\section{A Global Review of Cumulative Pressure and Impact Assessments in Marine Environments}

\author{
Samuli Korpinen ${ }^{1 *}$ and Jesper H. Andersen ${ }^{2}$ \\ ${ }^{1}$ Marine Research Center, Finnish Environment Institute, Helsinki, Finland, ${ }^{2}$ NIVA Denmark Water Research, Copenhagen, \\ Denmark
}

Ever more extensive use of marine space by human activities and greater demands for marine natural resources has led to increases in both duration and spatial extent of pressures on the marine environment. In parallel, the global crisis of decreasing biodiversity and loss of habitats has revitalized scientific research on human impacts and lead to methodological development of cumulative pressure and impact assessments (CPIA). In Europe alone, almost 20 CPIAs have been published in the past 10 years and some more in other sea regions of the world. In this review, we have analyzed 40 recent marine CPIAs and focused on their methodological approaches. We were especially interested in uncovering methodological similarities, identifying best practices and analysing whether the CPIAs have addressed the recent criticism. The review results showed surprisingly similar methodological approaches in half of the studies, raising hopes for finding coherence in international assessment efforts. Although the CPIA methods showed relatively few innovative approaches for addressing the major caveats of previous CPIAs, the most recent studies indicate that improved approaches may be soon found.

Keywords: human activities, pressures, multiple stressors, cumulative effects, impacts, ecosystem-based management

\section{INTRODUCTION}

Globally, the marine environment is at risk from multiple human activities such as overfishing, chemical contamination by hazardous substances, inputs of nutrients, physical modification, etc., in addition to climate change, leading to impaired environmental conditions (Lotze et al., 2006). Increasing human pressures leads to decreasing biodiversity and loss of habitats. A greater awareness of these problems has revitalized the scientific research on human impacts and led to an increasing number of laws, strategies and commitments to reduce human impacts on the ecosystem. The challenge for the scientific community lies in showing evidence of the causalities between human activities, the pressure they cause and the associated impacts on species and habitats, including humans and the human society. In the marine environment, the global assessment of human impacts by Halpern et al. (2008) fostered a wave of impact assessments in the world's seas (e.g., Selkoe et al., 2009; Ban et al., 2010; Korpinen et al., 2012). Although many of these assessments followed the same methodology as in the global assessment, new approaches were also found (e.g., Andersen and Stock, 2013; Knights et al., 2013), old approaches were re-assessed (e.g., van der Wal and Tamis, 2014) and spatial accuracy of the assessments increased 
(e.g., Ban et al., 2010). In this review, we have assessed 40 recent marine assessments of cumulative pressures and impacts and focused on the methodological approaches. We were especially interested in discovering methodological similarities, identifying good practices and proposing areas in need of more robust scientific input.

So-called cumulative pressure and impact assessments (CPIA) aim to cover additive, synergistic and antagonistic effects of multiple pressures on selected features of the ecosystem. In their fullest form, they attempt to cover all existing anthropogenic pressures and estimate their impacts on a wide spectrum of ecosystem components (e.g., Korpinen et al., 2012). More focused CPIAs assess specific species (Certain et al., 2015; Marcotte et al., 2015), communities (Giakoumi et al., 2015) or are limited to specific human activities (Benn et al., 2010) or pressures (Coll et al., 2016). The selection of ecosystem components in CPIAs is an important step, at least in case of selecting characterizing species to represent ecosystems, food webs or habitats, and hence, this review will also analyse the assessment methods in this respect.

The complexity of CPIAs has led to simplistic assumptions in the methods. Halpern and Fujita (2013) listed many of those and discussed the consequences of the assumptions for the overall assessment conclusions. For instance, many methods assume additivity of impacts, while meta-analytical studies indicate strong roles by synergistic and antagonistic effects (Crain et al., 2008). Similarly, the CPIAs analyzed typically assume that the impacts increase linearly with increasing pressures, while nonlinear responses seem to be more common in nature (Hunsicker et al., 2016). Despite these assumptions the CPIAs have provided robust outcomes which seem to correlate with the state-ofthe-environment assessments (Andersen et al., 2015) and have potential to inform management decisions.

CPIAs are primarily meant to inform decision-makers and guide management decisions. Therefore, the impacts should be traceable all the way to the human activities at sea, on the coast or in in the upstream catchments. Established links between human activities, pressures and ecosystem components are essential for effective and reliable CPIAs. These links are formed on the basis of causality (i.e., which human activities cause which pressures and which ecosystem components do they affect?), spatial overlap, or exposure (i.e., where are the activities, pressures, and ecosystem components located? Is uncertainty considered? How do the pressures decay from their source?) and sensitivity (i.e., how sensitive is a given ecosystem component to a specific pressure?). So far, only a few attempts to link these in a generalized and systematic way have been published (Knights et al., 2013, 2015) but some linkage frameworks have been in use by regional sea conventions for years (e.g., the North-East Atlantic, the Baltic Sea). Solid basis and transparent communication of these links is crucial for taking the message from the scientific community to the decision-making level. The progress in spatial data tools and online map services will certainly help in that task. Nonetheless, this review critically evaluated the activity-pressure-impact links of the CPIAs.

The cornerstone of CPIAs is the estimation of the potential impact of a specific pressure on a specific ecosystem component.
This has been estimated numerically on the basis of spatial damage or loss of individuals (e.g., Giakoumi et al., 2015; Coll et al., 2016) or categorically on the basis of literature reviews and expert panels (e.g., Halpern et al., 2007; Eno et al., 2013). The potential concerns with such a variety of approaches are, firstly, if the different estimate variables are comparable, and secondly, whether the validation (referred to by some authors as "groundtruthing") of the CPIAs to realistic "effect scales" is reliable. To our knowledge this is the first scientific review of the CPIAs and as such its general aim is to lay down an overview of the existing methods and practices.

\section{MATERIALS AND METHODS}

\section{Scope of the Review}

This review has the general aim to provide an overview of the methods and practices that are used to produce CPIAs in marine environments. It will not evaluate input data or assessment practices outside the methods, even though these may, nonetheless, have important functions in communication, transparency, and confidence of the assessments.

This review has five specific objectives: (1) To compare and find similarities in the structures of the CPIA methods; (2) to evaluate the selection of ecosystem components included in CPIAs; (3) to evaluate the links between human activities, pressures and associated impacts in the CPIAs; (4) to compare the methods in estimating potential impacts; and (5) to find good practices in validating the CPIAs. Each of these objectives is met by defining a number of research questions to be answered for each of the reviewed studies. The research questions are given in Table 1.

\section{Selection of Studies}

We reviewed CPIA studies which have been published after 2000 and included integration of at least two different pressures. We accepted studies which assess cumulative pressures or cumulative impacts but did not include concept papers unless they piloted a case study or gave an operational method formulation. We performed this search globally by the Google Scholar engine with key words "cumulative effect [/impact] on marine environment [/ecosystem]," "marine cumulative impact assessment," and "Halpern impact assessment of marine pressures." The search was limited to the period 2000-2016 and the results were asked in the order of relevance. The search gave thousands of matches, but we analyzed only 750 first hits and applied the above-mentioned exclusion/inclusion criteria. We also included studies which were cited in the found CPIAs and matched with our search criteria. In total, 35 peer-reviewed CPIA studies were found. However, we also noticed that many CPIA studies have been published as project reports or in institutions' report series due to the nature of this assessment field and those assessments included interesting methodological development. Therefore, we included five additional studies. Hence, our review included altogether 40 studies. Global distribution of the studies is given in Figure 1 and full references to the studies are given in the Supplementary Material (Appendix A). 
TABLE 1 | Specific research questions in the review.

1. Compare and find similarities in the structures of the CPIA methods
1.1 Does the method assess impacts or pressures?
1.2 What integration method the CPIAs have (separate, additive, synergistic,
antagonistic)?
1.3 What is the form of pressure-impact relation (categorical, linear, non-linear)?
2. Evaluate the selection of ecosystem components into CPIAs
2.1 Does the CPIA include impacts on species?
2.2 Does the CPIA include impacts on benthic habitats?
2.3 Does the CPIA include impacts on pelagic habitats?
3. Evaluate the links between human activities, pressures and associated impacts
in the CPIAs
3.1 Does the CPIA assess human activities?
3.2 Does the CPIA provide activity-pressure links?
3.3 Does the CPIA aggregate pressures from >1 human activities?
3.4 Is the CPIA built on an entire linkage framework of activities, pressures and
ecosystem components?
3.5 Does the CPIA benchmark pressure levels for impact estimates?
3.6 Does the CPIA provide a maximum value for pressures?
4. Compare the methods in estimating potential impacts
4.1 Are impact estimated based on expert judgment?
4.2 Are impact estimated based on literature reviews?
4.3 Are impact estimated categorical or continuously numerical?
5.1 Fine impact estimates derived from a model?
the environment?
What is the validation method?

The questions are categorized under the five objectives of the review.

\section{Evaluation Criteria}

Each of the studies were analyzed to find answers to the five specific objectives and research questions (Table 1). The five objectives were evaluated generally following the descriptions of the reviewed study methods but also a more specific analysis of the methods was made in order to see tabular summary information of the recent CPIAs and compare them against major assumptions of the CPIAs as listed by Halpern and Fujita (2013). In case of the cumulative pressure studies, we evaluated only the general structure (objective 1) and links between activities and pressures (objective 3), as the other objectives require an impact assessment. Full results of the analyses are annexed as Supplementary Material (Appendix A).

\section{Defining the Terms}

The scientific literature provides a wide range of terms for CPIAs. An extensive discussion on this is given by Judd et al. (2015), who also provide definitions for the whole pathway from sources (e.g., human activities) to pressures, effects, receptors (e.g., ecosystem components), and impacts. In this study, we use the term "human activity" instead of "source" and define "pressure" (following Judd et al., 2015) as "an event or agent (biological, chemical, or physical) exerted by the source to elicit an effect." Although an effect and an impact can be defined as different steps on the pathway, we have chosen to use the term "impact" in this review.
This is a pragmatic solution as our reviewed literature uses both these terms in justifiable way (sensu Judd et al., 2015).

\section{RESULTS}

\section{Similarities in the Structures of the CPIA Methods}

Of the 40 studies reviewed, 33 had assessments of cumulative impacts and seven assessed cumulative pressures. Most of the assessments ( $n=35,88 \%$ ) assumed cumulative pressures or impacts as additive and five assessments included synergistic or antagonistic effects (Figure 2). The synergistic and antagonistic effects were mainly assessed in those CPIAs which used ecosystem models, but in one study synergistic effects were inserted into an additive model by defining pressures enhancing the effects of other pressures (Certain et al., 2015). Most of the methods (93\%) also assumed linear relationships between activities, pressures and impacts (Figure 2). In one assessment the relationship was not clear and in two assessments the relationship was categorical. With the exception of four studies (Aubry and Elliott, 2006; Foden et al., 2011; Giakoumi et al., 2015; Knights et al., 2015), all the others made the assessments with varying spatial resolution (often by $0.2-2.5 \mathrm{~km}$ grid cells).

The CPIAs showed relatively similar structures. More specifically, $50 \%$ of the studies claimed that they follow the same method as in Halpern et al. (2008) or had a similar method (without directly referring to the Halpern study) (see Appendix A in Supplementary Material). These assessments consisted mainly of three components: (1) intensity of pressures ( $>1$ layers), (2) occurrence of ecosystem components ( $>1$ layers, only if impacts were assessed), and (3) some types of weighting factors to express impacts or to weight pressures. In those studies, where impacts were assessed, a weighting factor was produced for each specific pressure-ecosystem component combination, whereas in the pressure assessments the weighting factors were produced to balance threats between the pressures. The impact weighting factors were sometimes called "vulnerabilities" or "sensitivities" of the ecosystem components to pressures.

In addition, there were a few other methods which relied on similar additive-type models and will likely produce comparable assessment results (e.g., Zacharias and Gregr, 2005; Stelzenmuller et al., 2010; van der Wal and Tamis, 2014). Thus, there seems to be a mainstream approach in the CPIAs which is used worldwide (Figure 1), but where small adaptations have been applied in treating of input data and ecosystem sensitivity and in integrating these into the score of cumulative pressures or impacts.

\section{Selection of Species and Habitat Data into the CPIAs}

Cumulative impacts were assessed for benthic habitats in $76 \%$ of the impact assessments, but also species (41\%) and pelagic habitats (38\%) were included in the studies (Figure 3). Species, benthic habitats and pelagic habitats together were included in only $12 \%$ of the studies. Only two studies assessed an entire community, including all the major components to the model (sea grass ecosystem: Giakoumi et al., 2015; 3 exploited fish 


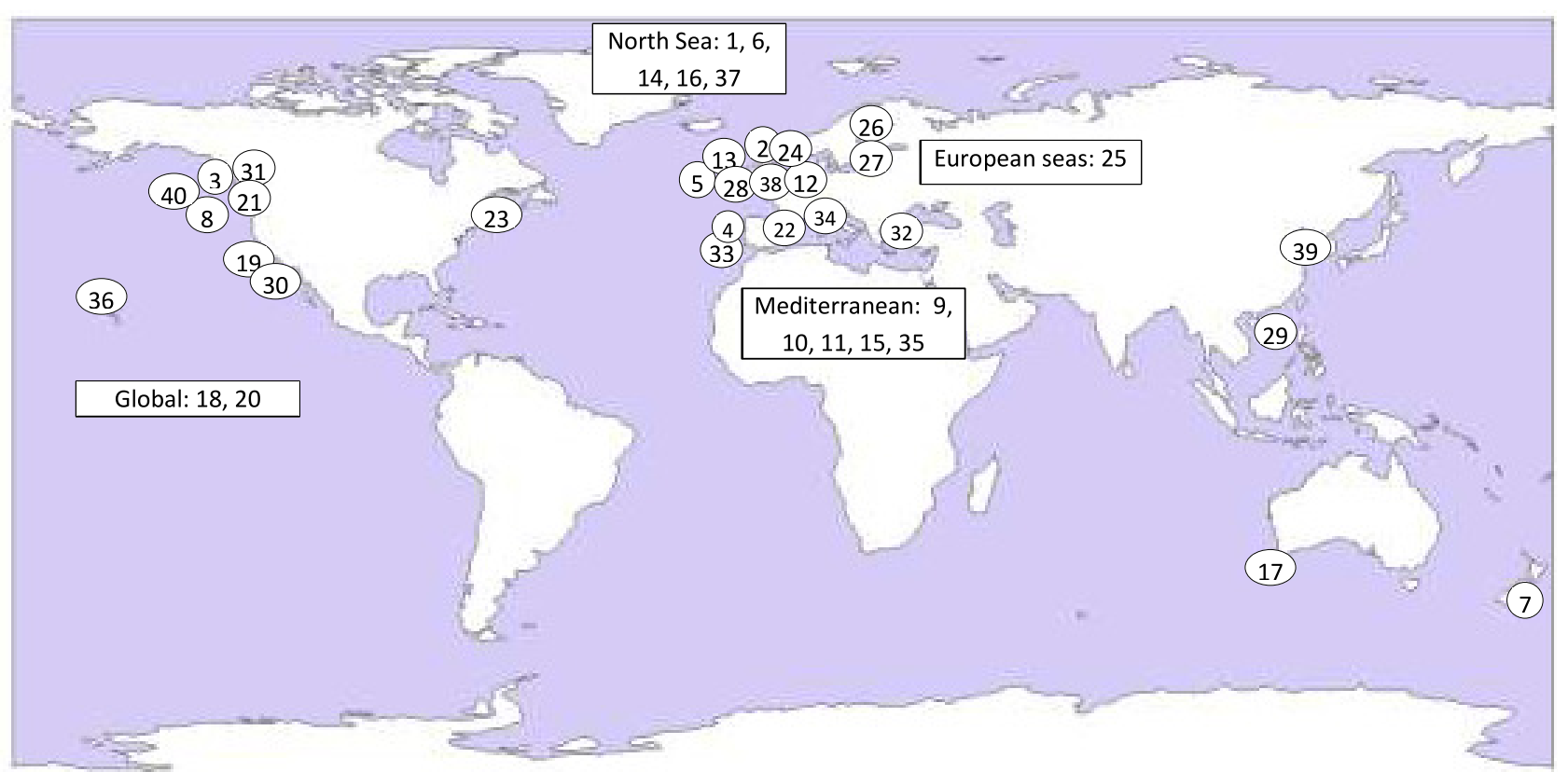

FIGURE 1 | Map with studies included in this review. Global studies and sea areas with several studies are shown in separate text boxes. Key: 1, Eastern North Sea (Andersen and Stock, 2013); 2, U.K. (Aubry and Elliott, 2006); 3, Canada's Pacific (Ban et al., 2010); 4, Portugal (Batista et al., 2014); 5, NE Atlantic (Benn et al., 2010); 6, North Sea (Certain et al., 2015); 7, New Zealand (Clark et al., 2016); 8, Canada's Pacific (Clarke Murray et al., 2015); 9, Mediterranean Sea (Claudet and Fraschetti, 2010); 10, Mediterranean Sea (Coll et al., 2012); 11, Mediterranean Sea (Coll et al., 2016); 12, Netherlands (de Vries et al., 2011); 13, UK (Eastwood et al., 2007); 14, UK (Foden et al., 2011); 15, Mediterranean (Giakoumi et al., 2015); 16, North Sea (Goodsir et al., 2015); 17, SE Australia (Griffith et al., 2012); 18, Global (Halpern et al., 2008); 19, California Current (Halpern et al., 2009); 20, Global (Halpern et al., 2015); 21, Washington US (Hayes and Landis, 2004); 22, French Mediterranean (Holon et al., 2015); 23, Massachusetts (Kappel et al., 2012); 24, Scotland (Kelly et al., 2014); 25, European seas (Knights et al., 2015); 26, Baltic Sea (Korpinen et al., 2012); 27, Baltic Sea (Korpinen et al., 2013); 28, Netherland (Lindeboom, 2005); 29, Hong Kong (Marcotte et al., 2015); 30, California Current (Maxwell et al., 2013); 31, Puget Sound, Canada's Pacific (McManus et al., 2014); 32, Mediterranean Sea and Black Sea (Micheli et al., 2013); 33, Spain (Moreno et al., 2012); 34, Liguarian Sea (Parravicini et al., 2011); 35, Mediterranean Sea (Rodríguez-Rodríguez et al., 2015); 36, Hawaii (Selkoe et al., 2009); 37, North Sea (Stelzenmuller et al., 2010); 38, Noth Sea (van der Wal and Tamis, 2014); 39, Jiaozhou Bay, North Yellow Sea (Wu et al., 2016); 40, (Zacharias and Gregr, 2005). Map from Natural Earth (free vector and raster map data @ naturalearthdata.com).

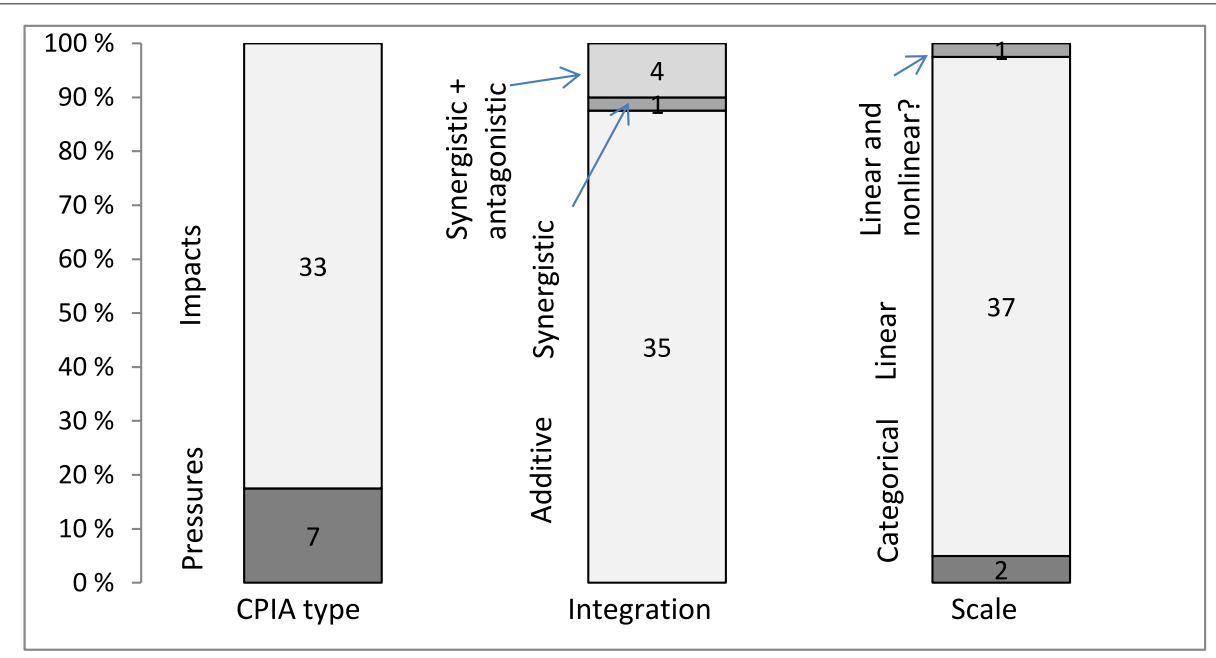

FIGURE 2 | Summary information of the $\mathbf{4 0}$ cumulative pressure and impact assessments (CPIA) included in the review. The CPIA type is divided into pressure and impact assessments. The integration was additive, synergistic or synergistic, and antagonistic. The scale of the pressure-impact relationship is divided into categorical, linear and linear and non-linear (with some uncertainty of this indicated by ?-mark). 


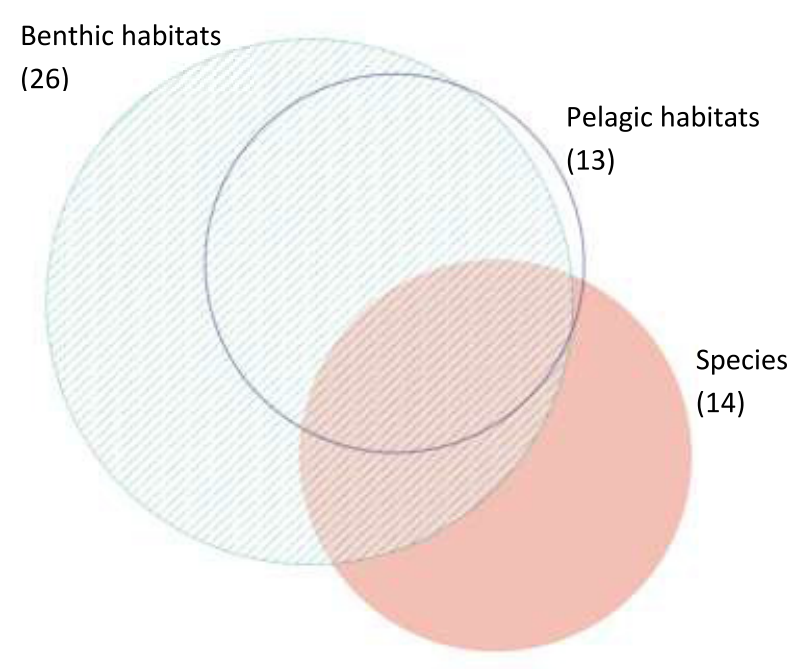

FIGURE 3 | Venn diagram for the inclusion of ecosystem components (species/species groups, benthic habitats, and pelagic habitats) in the reviewed CPIAs. Note that the number of studies in the figure is $>40$, because a CPIA can assess all the categories. Source of the Venn diagram: EulerAPE (http://www.eulerdiagrams.org/eulerAPE/).

species: Coll et al., 2016). Obviously all of the CPIAs had a limited number of ecosystem components in the assessments, but $21 \%$ of them had focused only on a species group (e.g., Zacharias and Gregr, 2005; Coll et al., 2012) or a single species only (Marcotte et al., 2015). However, many of the studies claimed to be demonstration studies and, hence, the selection of ecosystem components was made on practical grounds. Only in one study, a specific justification was given on the grounds of cultural, biological and legal arguments (Hayes and Landis, 2004). Nevertheless, there seemed to be a common lack of precise justification in the reviewed CPIAs, why some species or habitats were selected and others not.

\section{Have the CPIAs Defined Linkages between Activities, Pressures and Impacts?}

Ten studies (25\%) had defined all the linkages between human activities, pressures and impacts and made a framework to support the CPIA. All of the 10 CPIAs were assessments and not demonstration studies (see Appendix A in Supplementary Material). Additionally, nine more studies had covered all the human activities or all the pressures in the area but not linked them in a systematic way. However, in many cases, it was not possible to estimate whether the systematic framework was made outside the study and used in a more limited way. The review showed that the actual CPIA have taken seriously the linkages between activities, pressures and ecosystem components, often consulting local experts or making extensive literature surveys (e.g., Selkoe et al., 2009; McManus et al., 2014).

In summary of the review results, human activities were included in 31 studies (78\%), 26 studies (65\%) linked pressures to the human activities and 30 studies (75\%) had defined the human pressures into general pressure categories, for instance according to the EU Marine Strategy Framework Directive (MSFD).

Only one study had considered the maximum potential value of pressures (Clark et al., 2016). This is a necessary step in the CPIA procedure if pressures are quantified. Hence, almost all of the reviewed studies assumed that the maximum pressure value in the assessment area is the maximal intensity of that pressure. Moreover, while the majority of studies had normalized the pressure intensities (e.g., 0-1), none of the studies had benchmarked the pressures in order to estimate the impacts in a comparable way (i.e., defined the level of pressure where the impacts occur; see Halpern and Fujita, 2013). One of the studies asked experts to estimate impacts on a "typical level of pressures" (Andersen and Stock, 2013). The lack of definite benchmarks is especially problematic in case of non-linear relation of pressures and impacts. If the relation is non-linear, for instance logarithmic, a relatively low level of pressure can cause high impacts and the magnitude of impact does not increase much at higher pressure levels. However, most of the reviewed CPIAs assumed a linear increase of impacts as a pressure increases. This simplifies the impact formula, where each pressure can be given a single sensitivity score (for each ecosystem component combination).

\section{Estimation of Impacts}

We analyzed whether the CPIA studies estimated impacts from anthropogenic pressures by expert judgment or based on scientific literature. Of the 35 studies giving some kind of a weight factor (for impacts or pressures), 23 CPIAs (66\%) relied on expert judgment, and 14 (40\%) on literature (Figure 4). In two studies, the experts were informed by a review of scientific literature (See Appendix A in Supplementary Material).

Impact estimates were most often (69\%) categorical expressions of the sensitivity of the ecosystem components to the pressures or severity of the pressures on ecosystem components (Figure 4). Continuous impact scales were used in $31 \%$ of the studies and in these CPIAs the impacts were often estimated either from a few known parameters, such as mortality (e.g., de Vries et al., 2011), biomass change (Coll et al., 2016), or loss of habitat area (e.g., van der Wal and Tamis, 2014). In these studies, the scope of the CPIA was more limited, focusing on a few ecosystem components (a single species or a species group), of which the impact parameter (e.g., mortality) could be estimated. The more diverse ecosystem components there were in the CPIA studies, e.g., both species and habitats, the more the studies relied on categorical or semi-quantitative impact/sensitivity categories.

Five of the 33 studies (15\%), which assessed cumulative impacts, used meta-analyses or an ecosystem model to estimate impacts. The ecosystem models included, for instance, fishing effects on commercially exploited fish species (Coll et al., 2016) and main threats to the seagrass food web (Giakoumi et al., 2015). In one study, pressures were linked to biological quality indicators and the relationship was modeled (Parravicini et al., 2011). This model was used to predict impacts when the pressures were changed. 


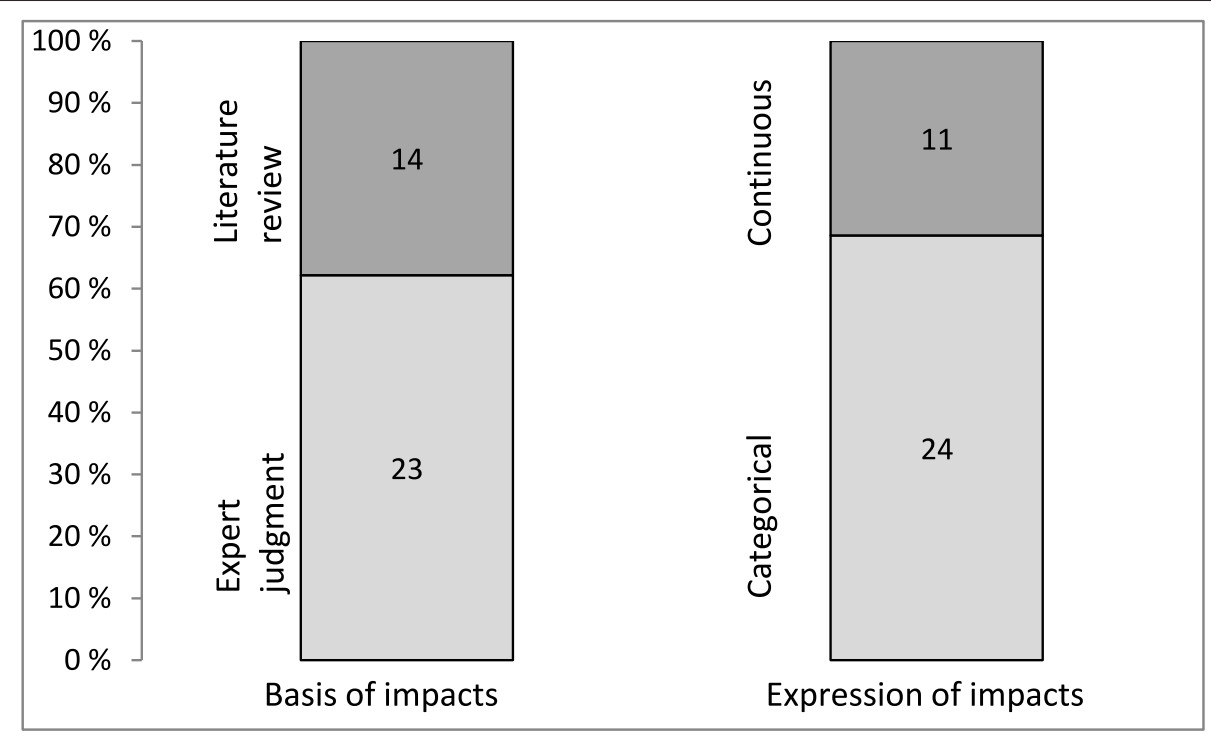

FIGURE 4 | Differences in estimating and expressing impacts of anthropogenic pressures. The impact estimates are based on expert judgment or literature (including models where the interactions are literature-based). The impacts are expressed on categorical scales and on continuous scales. Note that the numbers also include those studies where "impacts" are not specific to ecosystem components but used to weight pressures. Two of the studies used both literature and expert judgment as the basis.

\section{Validation of the Impacts}

Only 8 of the 40 studies (20\%) had validated the results, i.e., compared the cumulative impact (or pressure) scores with observed environmental status and then re-categorized the impact gradient into a realistic scale (Appendix A in Supplementary Material). However, three of the eight validated CPIAs used a scale obtained from another study and made no reanalysis in their own study. Thus, in reality, only five studies had really validated their impact scores with environmental status assessments. In addition, two more studies indicated how the validation should be made but did not apply it (Zacharias and Gregr, 2005; Claudet and Fraschetti, 2010).

The best description of validation was given by Clark et al. (2016) who compared the cumulative impact scores (on benthic habitats) with benthic fauna data. They found significant relationships between the benthic community composition based on Bray-Curtis similarities and the cumulative impacts by using non-parametric regression (DISTLM). This was also used to test the relation of individual standardized pressures to macro fauna data, without including the habitat sensitivity information to the pressure data. Clark et al. (2016) argue that validation may result in relatively weak relationships if the range of stressor levels is small, which is often the case in local studies. A large-scale validation was applied by Andersen et al. (2015) on a Baltic Sea-wide scale, where cumulative impact scores for sub-basins were compared with integrated state of marine biodiversity. In that scale, the relationship was significant, but due to the small number of sub-basins $(N=9)$, it was not possible to make conclusions about thresholds or tipping points.

\section{DISCUSSION}

Identification of marine areas that are sensitive and vulnerable to human activities is not a novelty; environmental sensitivity indices were launched already in the 1970s (Gundlach and Hayes, 1978). Cumulative assessments of multiple pressures and their impacts were carried out already in 1990s (e.g., Wiegers et al., 1998). Methodological development did not, however, receive wide attention until the 2000s when series of CPIAs were produced after the global impact assessment (Halpern et al., 2008). As shown in this review of 36 CPIAs in 2000s, more than half of them were based on the method by Halpern et al. (2008). However, similar research threads had already been started elsewhere (e.g., Lindeboom, 2005; de Vries et al., 2011; van der Wal and Tamis, 2014; Certain et al., 2015) and in comparison to these earlier methods, it is interesting to note that the method presented in Halpern et al. (2008) has allowed wider assessments in terms of human activities, pressures and ecosystem components than the other methods which tend to produce more focused (and sometimes more detailed) assessments in terms of activities, pressures and ecosystem components. Also various ecosystem models have this same limitation.

The review showed that the CPIAs have, in general, three essential components: spatial data on intensity of pressures, spatial data on occurrence of ecosystem components, and factors estimating impacts. In all of the three components, many of the reviewed CPIAs used simplified assumptions (see Halpern and Fujita, 2013) and had small differences in the approaches. Nonetheless, the majority of the studies, at least the ones based on additive integration and estimates of habitat sensitivity, can be 
expected to produce relatively comparable results and one can see potential improvements to the general method in the most recent studies. Although the 40 reviewed CPIAs were published between 2004 and 2016, 30\% of them were from the 2 most recent years and these contained novel approaches more often than the earlier CPIAs. Such approaches were, for instance, the use of fuzzy logic for impact occurrence (Marcotte et al., 2015), building on a fixed linkage framework (Goodsir et al., 2015), separating habitat recovery to a specific assessment (Knights et al., 2015), using food web models (Coll et al., 2016) or other statistical methods (Wu et al., 2016) and describing good practices in validation and pressure quantification (Clark et al., 2016).

\section{Treatment of Spatial Input Data}

In the pressure data sets, the main assumptions relate to the spatial extent of pressures from their sources, quantification of the pressures (often on the basis of underlying human activities) and the normalization of the pressures. Spatial extent of pressures has often been treated as a linear decaying model from the source, whereas e.g., Andersen and Stock (2013) produced five alternative models which were used for different types of pressures. The quantification of pressures on the basis of human activities is an assumption which is difficult to replace by real pressure data. No monitoring programme can be expected to measure, e.g., resuspension from bottom-trawling and, hence, fishing activity data is used to estimate the pressure. The pressures are then normalized to a dimensionless scale in order to make them comparable with other pressures, measured in other units. The most frequently used approach was to scale the pressure values linearly such that the highest value is equal to 1.0. Obviously, the main problem with this method is the assumption that the data set contains the maximum value of that pressure. In reality, the pressures in the assessment period may be much lower than the long-term maximum if management measures have been implemented. Among the studies in this review, Clark et al. (2016) was the only CPIA setting a theoretical maximum value for each of the pressure data sets. In addition, Halpern et al. (2015) normalized the pressures according to the highest value of two data sets to allow temporal comparison of two assessment periods.

Occurrence of ecosystem components-species and habitats-in the assessment units determines whether an impact can take place in that area. The occurrence of the habitats was in all the cases reported as presence/absence, whereas for species occurrence probabilities were also applied (Andersen and Stock, 2013). Even though no CPIA used a probability scale for habitat presence, this could be applied if the habitat presence is uncertain due to the low confidence in the input data. Only a few of the reviewed CPIAs (9\%) targeted the entire marine ecosystem, i.e., species, benthic, and pelagic habitats. The majority of the studies (55\%) focused solely on benthic and pelagic habitats and $21 \%$ included species only. Because of the additive approach in most of the CPIAs, a major difference is also the choice to use only benthic habitat layers over the entire assessment area with only one habitat type in a grid cell (e.g., Korpinen et al., 2013) or, alternatively, to use several overlapping layers of ecosystem components and several ecosystem components per grid cell (e.g., Halpern et al., 2008). In the former, the resulting cumulative impacts are relatively simple to interpret, because all the impact scores indicate the amount of pressures, whereas in the latter case one needs to consider also the diversity of ecosystem components in an area when interpreting the cumulative impacts. Both of the approaches are conceptually correct, but they tell slightly different stories from the anthropogenic pressures.

\section{How Vulnerability Is Assessed?}

There are basically two types of differences in integrating impacts from multiple pressures: using similar endpoints (same variables) from all the pressures or integrating categorized impacts of different types of variables. In this review, these two basic categories were found and further divided to more detailed sub-types: (1a) categorical expressions of potential impacts on ecosystem components, where the impacts have been usually defined by 3-5 criteria (e.g., functional impact, resistance, recoverability and frequency; e.g., Halpern et al., 2007); (1b) categorical expressions of habitat sensitivity, which has been defined by resistance and resilience (e.g., Stelzenmuller et al., 2010, see also Eno et al., 2013); (2a) numeric estimate of impact by a measurable variable (e.g., proportion of disturbed sea floor; van der Wal and Tamis, 2014, or change in biomass in Coll et al., 2016); and (2b) effect sizes of impacts in a metaanalysis (e.g., Claudet and Fraschetti, 2010). The two former methods are comparable, both considering categorical estimates of sensitivity of the ecosystem component, while the two latter ones use data-based approaches. These latter approaches share the limitation that common parameters are difficult to find for multiple pressures. So far, the quantitative, data-based CPIAs have not been applied to more than a few pressures or ecosystem components, which has limited their usefulness for getting a wider view of human impacts on marine environment.

There has been considerable progress in recent years in developing sensitivity estimates for species and benthic habitats. Zacharias and Gregr (2005) defined the terms sensitivity and vulnerability in an explicit and quantifiable manner with the aim to produce a tool that can predict and quantify vulnerable marine areas (VMA). Using the same or similar definitions, Tyler-Walters and Jackson (1999), Tillin et al. (2010), Eno et al. (2013), and La Rivière et al. (2016) have defined parameters for sensitivity estimates and procedures how these can be assigned to broader habitat types, which are usually the only available mapped marine habitats. Also the meta-analytical approach has been used by Claudet and Fraschetti (2010) to produce datadriven impact estimates for the Mediterranean Sea. Despite the progress, these were used very little, if at all, in the reviewed CPIAs.

\section{Needs for Further Progress in CPIA Methodology}

The review showed that none of the CPIAs had benchmarked the pressures (i.e., a quantitative definition of a certain level of pressure, for which the impact or sensitivity is estimated). This is especially problematic for CPIAs which assessed very different types of activities causing same types of pressures. For 
example, siltation of seabed is caused by laying cables on sea floor, bottom-trawling, dredging and disposal of dredged material (to name a few activities), but the amount of sedimentation varies between the activities, i.e., a low pressure for each activity, if measured by different parameters, may mean different amounts of sediment and, hence, different impacts. This difference in activities was normally addressed in the reviewed CPIAs by giving different sensitivity scores for the pressures from different activities. This is an adequate "fix" if the impacts from pressures increase linearly. However, in non-linear cases, this assumption is no longer valid. This challenge was addressed by Tillin et al. (2010) who proposed to divide pressures to 2-3 sub-pressures based on their magnitude and define benchmarks for these pressures in order to give sharper and more comparable estimates of habitat sensitivity. For example, sea-floor abrasion was sub-divided to "penetration of the seabed surface," "shallow abrasion/penetration of the seabed surface" and "surface abrasion," and benchmarks to these were defined as " $>25 \mathrm{~mm}$ penetration," " $\leq 25 \mathrm{~mm}$ penetration," and "surface damage." The approach by Tillin et al. (2010) was taken up by La Rivière et al. (2016) and gives an easily approachable method for CPIAs where habitat sensitivity is defined by expert judgment.

The element of time was not very visible in the reviewed CPIAs. As data sources of human activities and pressures are often imprecise with regard to time of occurrence and duration, the CPIAs assume that pressures are long-lasting and overlap in time. This may well be the case with long-lasting impacts, i.e., with long recovery times, but many of the pressures and impacts are relatively short-lived (e.g., noise, siltation in exposed shores). Such an assumption can be considered as a conservative approach, but some realism could be introduced by specifying impacts seasonally (de Vries et al., 2011) or assessing the potential recovery separately (Knights et al., 2015). A more difficult aspect is the potential accumulation of effects in time (Eastwood et al., 2007). Although difficult to quantify, this was addressed by at least Korpinen et al. (2012) by summing certain pressures over the assessment period when preparing the input data.

An issue in regard to assessing vulnerability which has not been addressed by any of the reviewed studies is the question of historical impacts which have already modified the marine environment. This is especially problematic for the spatial ecosystem data, which only reflects the current situation. In addition, the question of how to assess extinct species or significantly reduced habitat coverage was not addressed by any of the reviewed studies. This specific weakness is something that needs to be solved.

\section{Criticism against the Major Assumptions in CPIAs}

Five years after the global map of human impacts (Halpern et al., 2008), a paper was published criticizing the major assumptions in CPIAs (Halpern and Fujita, 2013). The authors listed nine major assumptions in the CPIAs, which are: (1) Stressor layers are of roughly equal importance, (2) Uniform distribution of stressors within a pixel, (3) Habitats either exist or are absent in a pixel, (4) Transforming and normalizing stressors, (5) Linear response of ecosystems to stressors, (6) Consistent ecosystem response, (7) Vulnerability weights sufficiently accurate, (8) Additive model, and (9) Linear response of ecosystems to cumulative impacts. For more detailed description and examples of these assumptions, readers are invited to read the full paper, but here we can briefly analyse how well the studies of this review, especially those published after 2013, have addressed these assumptions.

In this review, we saw that fairly few studies had included the full array of pressures in the assessment. Those that did this had commonly built a linkage framework between activities and pressures and aimed to aggregate pressures from several activities (addressing assumption \#1). This is a tedious task if done properly, as described by Tillin et al. (2010). Assumptions $\# 2$ and \#3 deal with the spatial resolution of input data and these aspects were not included in this review. However, assumptions \#4 and \#5 relate directly to the core of this review and may cause under- or overestimation of cumulative impacts, as they are related to the estimation of impacts at different pressure magnitudes. According to our review results, none of the studies addressed non-linear responses between pressures and impacts (as far as we were able to interpret the methods). Assumption \#6 is about consistent impacts in different areas and within the definitions of the ecosystem components. Although being a critical assumption, none of the reviewed studies really addressed this in their methodology. However, some of the CPIAs were geographically limited and local experts were involved in making the impact estimates (e.g., Selkoe et al., 2009; McManus et al., 2014), which may mitigate the potential error. This does not, however, answer the other side of the assumption that impacts should be consistent within broad habitat definitions (which is definitely a bold assumption). In case of the broad-scale benthic or pelagic habitats, Tillin et al. (2010) and La Rivière et al. (2016) suggest the use of "characterizing species" as targets of the sensitivity estimation, but this has not, to our knowledge, been applied in any published CPIA. Assumption \#7 raises the concern that expert-based impact estimates are not coherent or accurate. According to our review, $40 \%$ of the studies based these estimates on literature while $66 \%$ used expert elicitation. None of the studies claimed any comparison between the two approaches but two studies used both the approaches. Assumptions \#8 and \#9 have already been discussed in this study, but briefly, $88 \%$ of the studies assumed additivity and after 2013 only 3 of the 15 studies included synergistic and/or antagonistic effects. Nevertheless, this can be seen as an improvement in CPIA development, as before 2013 only one of the reviewed studies addressed these effects. The inclusion of non-linear responses to the pressure-impact relationship had not, according to our results, progressed at all.

The current CPIA practices are obviously limited by the scientific knowledge we have today, but there are theoretically unlimited possibilities of impacts on diverse marine environment. To tackle the challenge the methods should focus on keystone species and habitats and build on uncertainty assessment principles and a structured approach to filter and 
prioritize pressures, impacts and ecosystem components (see Wiegers et al., 1998; Judd et al., 2015). In this review we saw still diverse approaches and non-structured methods but also some positive signs.

\section{CONCLUSIONS AND OUTLOOK}

Our review showed that despite rapid method development and several recent publications of CPIA around the world, the assessments still rely on major assumptions which may potentially bias the results (Halpern and Fujita, 2013). Only the most recent studies had started developing methods to address the caveats.

We also showed that the assessment published by Halpern et al. (2008) is gradually developing into a global standard, especially taking some of the recent assessments into consideration. Recalling the concerns raised by Halpern and Fujita (2013), this standard would, however, need new openings such as the inclusion of non-linearity to the models or the use of other types of broad modeling frameworks, e.g., Bayesian Belief Networks, in CPIAs (Uthicke et al., 2016). The direction in the most recent studies indicates that this may indeed be the case in the near future.

In the light of this review, there are currently, in our understanding, no other methods capable to assess the whole range of human impacts than the ones similar to Halpern et al. (2008). Hence, we call not only for a further development of the methodology but also a sharing of tools or codes, such

\section{REFERENCES}

Andersen, J. H., and Stock, A. (eds.) (2013). Human Uses, Pressures and Impacts in the Eastern North Sea. Technical Report, Danish Centre for Environment and Energy, Aarhus University, Roskilde, 134.

Andersen, J. H., Halpern, B. S., Korpinen, S., Murray, C., and Reker, J. (2015). Baltic Sea biodiversity status vs. cumulative human pressures. Estuar. Coast. Shelf Sci. 161, 88-92. doi: 10.1016/j.ecss.2015.05.002

Aubry, A., and Elliott, M. (2006). The use of environmental integrative indicators to assess seabed disturbance in estuaries and coasts: application to the Humber Estuary, UK. Mar. Pollut. Bull. 53, 175-185. doi: 10.1016/j.marpolbul.2005.09.021

Ban, N. C., Alidina, H. M., and Ardron, J. A. (2010). Cumulative impact mapping: advances, relevance and limitations to marine management and conservation, using Canada's Pacific waters as a case study. Mar. Policy 34, 876-886. doi: 10.1016/j.marpol.2010.01.010

Batista, M. I., Henriques, S., Pais, M. P., and Cabral, H. P. (2014). Assessment of cumulative human pressures on a coastal area: integrating information for MPA planning and management. Ocean Coast. Manage. 102, 248-257. doi: 10.1016/j.ocecoaman.2014.09.020

Benn, A. R., Weaver, P. P., Billet, D. S. M., van den Hove, S., Murdock, A. P., Doneghan, G. B., et al. (2010). Human activities on the deep seafloor in the North East Atlantic: an assessment of spatial extent. PLoS ONE 5:e12730. doi: 10.1371/journal.pone.0012730

Certain, G., Jørgensen, L. L., Christel, I., Planque, B., and Bretagnolle, V. (2015). Mapping the vulnerability of animal community to pressure in marine systems: disentangling pressure types and integrating their impact from the individual to the community level. ICES J. Mar. Sci. 72, 1470-1482. doi: 10.1093/icesjms/ fsv003 as the open access EcoImpactMapper (Stock, 2016), as this will encourage and support both a short term process focusing on the tools and a long-term process supporting CPIA-based marine ecosystem health assessment as well as evidence-based management.

\section{AUTHOR CONTRIBUTIONS}

SK: the main author responsible for the analysis and the results. JA: building the study database, supporting the analysis and text, responsible for visual presentation.

\section{ACKNOWLEDGMENTS}

We are grateful to Johnny Reker, Andy Stock, and Ciaran Murray in supporting us in the work leading to this review. Also the ongoing work within the European Topic Center for Inland, Costal and Marine waters provided a fruitful context for the authors. Financial support from the HELCOM TAPAS project (07.0201/2015/717804/SUB/ENVC.2) and the FP7 DEVOTES project $\left(\mathrm{n}^{\circ} 308392\right)$ helped the authors in carrying out this review.

\section{SUPPLEMENTARY MATERIAL}

The Supplementary Material for this article can be found online at: http://journal.frontiersin.org/article/10.3389/fmars. 2016.00153

Clark, D., Goodwin, E., Sinner, J., Ellis, J., and Singh, G. (2016). Validation and limitations of a cumulative impact model for an estuary. Ocean Coast. Manage. 120, 88-98. doi: 10.1016/j.ocecoaman.2015.11.013

Clarke Murray, C., Agbayani, S., Alidina, H. M., and Ban, N. C. (2015). Advancing marine cumulative effects mapping: an update in Canada's Pacific waters. Mar. Policy 58, 71-77. doi: 10.1016/j.marpol.2015.04.003

Claudet, J., and Fraschetti, S. (2010). Human-driven impacts on marine habitats: a regional meta-analysis in the Mediterranean Sea. Biol. Conserv. 143, 2195-2206. doi: 10.1016/j.biocon.2010.06.004

Coll, M., Piroddi, C., Albouy, C., Lasram, F. B. R., Cheung, W., Christensen, V., et al. (2012). The Mediterranean Sea under siege: spatial overlap between marine biodiversity, cumulative threats and marine reserves. Glob. Ecol. Biogeogr. 21, 465-480. doi: 10.1111/j.1466-8238.2011.00697.x

Coll, M., Steenbeek, J., Sole, J., Palomera, I., and Christensen, V. (2016). Modelling the cumulative spatial-temporal effects of environmental drivers and fishing in a NW Mediterranean marine ecosystem. Ecol. Indic. 331, 100-114. doi: 10.1016/j.ecolmodel.2016.03.020

Crain, C. M., Kroeker, K., and Halpern, B. S. (2008). Interactive and cumulative effects of multiple human stressors in marine systems. Ecol. Lett. 11, 1304-1315. doi: 10.1111/j.1461-0248.2008.01253.x

de Vries, P., Tamis, J. E., van der Wal, J. T., Jak, R. G., Slijkerman, D. M. E., and Schobben, J. H. M. (2011). Scaling Human-Induced Pressures to Population Level Impacts in the Marine Environment. Implementation of the Prototype CUMULEO-RAM Model. Werkdocument 285. Wageningen: Wettelijke Onderzoekstaken Natuur and Milieu, 80.

Eastwood, P. D., Mills, C. M., Aldridge, J. N., Houghton, C. A., and Rogers, S. I. (2007). Human activities in UK offshore waters: an assessment of direct, physical pressure on the seabed. ICES J. Mar. Sci. 64, 453-463. doi: 10.1093/icesjms/fsm001 
Eno, N. C., Frid, C. L. J., Hall, K., Ramsay, K., Sharp, R. A. M., Brazier, D. P., et al. (2013). Assessing the sensitivity of habitats to fishing: from seabed maps to sensitivity maps. J. Fish Biol. 83, 826-846. doi: 10.1111/jfb.12132

Foden, J., Rogers, S. I., and Jones, A. P. (2011). Human pressures on UK seabed habitats: a cumulative impact assessment. Mar. Ecol. Prog. Ser. 428, 33-47. doi: 10.3354/meps09064

Giakoumi, S., Halpern, B. S., Michel, L. N., Gobert, S., Sini, M., Boudouresque, C.-F., et al. (2015). Towards a framework for assessment and management of cumulative human impacts on marine food webs. Conserv. Biol. 29, 1228-1234. doi: $10.1111 /$ cobi. 12468

Goodsir, F., Bloomfield, H. J., Judd, A. D., Kral, F., Robinson, L. A., and Knights, A. M. (2015). A spatially-resolved pressure-based approach for the identification and management of combined effects arising from multiple human activities. ICES J. Mar. Sci. 72, 2245-2256. doi: 10.1093/icesjms/fsv080

Griffith, G. P., Fulton, E. A., Gorton, R., and Richardson, A. J. (2012). Predicting interactions among fishing, Ocean Warming, and Ocean Acidification in a marine system with whole-ecosystem models. Conserv. Biol. 26, 1145-1152. doi: 10.1111/j.1523-1739.2012.01937.x

Gundlach, E. R., and Hayes, M. O. (1978). Vulnerability of coastal environments to oil spill impacts. Mar. Technol. Soc. J. 12, 18-25.

Halpern, B. S., Frazier, M., Potapenko, J., Casey, K. S., Koenig, K., Longo, C., et al. (2015). Spatial and temporal changes in cumulative human impacts on the world's ocean. Nat. Commun. 6, 7615. doi: 10.1038/ncomms 8615

Halpern, B. S., and Fujita, R. (2013). Assumptions, challenges, and future directions in cumulative impact analysis. Ecosphere 4, 1-11. doi: 10.1890/ES13-00181.1

Halpern, B. S., Kappel, C. V., Selkoe, K. A., Micheli, F., Ebert, C. M., Kontgis, C., et al. (2009). Mapping cumulative human impacts to California Current marine ecosystems. Conserv. Lett. 2, 138-148. doi: 10.1111/j.1755-263X.2009.00058.x

Halpern, B. S., Selkoe, K. A., Micheli, F., and Kappel, C. V. (2007). Evaluating and ranking the vulnerability of global marine ecosystems to anthropogenic threats. Conserv. Biol. 21, 1301-1315. doi: 10.1111/j.1523-1739.2007. 00752.x

Halpern, B. S., Walbridge, S., Selkoe, K. A., Kappel, C. V., Micheli, F., D’Agrosa, C., et al. (2008). A global map of human impact on marine ecosystems. Science 319, 948-952. doi: 10.1126/science.1149345

Hayes, E. H., and Landis, W. G. (2004). Regional ecological risk assessment of a near shore marine environment: Cherry Point, WA. Hum. Ecol. Risk Assess. 10, 299-325. doi: 10.1080/10807030490438256

Holon, F., Mouquet, N., Boissery, P., Bouchoucha, M., Delaruelle, G., Tribot, A.-S., et al. (2015). Fine-scale cartography of human impacts along French Mediterranean Coasts: a relevant map for the management of marine ecosystems. PLoS ONE 10:e0135473. doi: 10.1371/journal.pone.01 35473

Hunsicker, M. E., Kappel, C. V., Selkoe, K. A., Halpern, B. S., Scarborough, C., Mease, L., et al. (2016). Characterizing driver-response relationships in marine pelagic ecosystems for improved ocean management. Ecol. Appl. 26, 651-663. doi: 10.1890/14-2200

Judd, A. D., Backhaus, T., and Goodsir, F. (2015). An effective set of principles for practical implementation of marine cumulative effects assessment. Environ. Sci. Policy 54, 254-262. doi: 10.1016/j.envsci.2015.07.008

Kappel, C. V., Halpern, B. S., and Napoli, N. (2012). Mapping Cumulative Impacts of Human Activities on Marine Ecosystems. NCEAS Research Report 3. Boston: SeaPlan.

Kelly, C., Gray, L., Shucksmith, R. J., and Tweddle, J. F. (2014). Investigating options on how to address cumulative impacts in marine spatial planning. Ocean Coast. Manage. 102, 139-148. doi: 10.1016/j.ocecoaman.2014. 09.019

Knights, A. M., Koss, R. S., and Robinson, L. A. (2013). Identifying common pressure pathways from a complex network of human activities to support ecosystem-based management. Ecol. Appl. 23, 755-765. doi: 10.1890/ 12-1137.1

Knights, A. M., Piet, G. J., Jongbloed, R., Tamis, J. E., Churilova, T., FlemingLehtinen, V., et al. (2015). An exposure-effect approach for evaluating ecosystem-wide risks from human activities. ICES J. Mar. Sci. 72, 1105-1115. doi: 10.1093/icesjms/fsu245

Korpinen, S., Meidinger, M., and Laamanen, M. (2013). Cumulative impacts on seabed habitats: an indicator for assessments of good environmental status. Mar. Pollut. Bull. 74, 311-319. doi: 10.1016/j.marpolbul.2013.06.036
Korpinen, S., Meski, L., Andersen, J. H., and Laamanen, M. (2012). Human pressures and their potential impact on the Baltic Sea ecosystem. Ecol. Indic. 15, 105-114. doi: 10.1016/j.ecolind.2011.09.023

La Rivière, M., Aish, A., Gauthier, O., Grall, J., Guérin, L., Janson, A.-L., et al. (2016). Assessing Benthic Habitats' Sensitivity to Human Pressures: A Methodological Framework. Summary report. Rapport SPN 2016-87, MNHN. Paris, 42.

Lindeboom, H. J. (2005). "Comparison of effects of fishing with effects of natural events and non-fishing anthropogenic impacts on benthic habitats," in American Fisheries Society Symposium, Vol. 41 (Bethesda, MD), 609-617.

Lotze, H. K., Lenihan, H. S., Bourque, B. J., Bradbury, R. H., Cooke, R. G., Kay, M. C., et al. (2006). Depletion, degradation, and recovery potential of Estuaries and Coastal Seas. Science 312, 1806-1809. doi: 10.1126/science.1128035

Marcotte, D., Hung, S. K., and Caquard, S. (2015). Mapping cumulative impacts on Hong Kong's pink dolphin population. Ocean Coast. Manage. 109, 51-63. doi: 10.1016/j.ocecoaman.2015.02.002

Maxwell, S. M., Hazen, E. L., Bograd, S. J., Halpern, B. S., Breed, G. A., Nickel, B., et al. (2013). Cumulative human impacts on marine predators. Nature 4, 2688. doi: $10.1038 /$ ncomms 3688

McManus, E., Jenni, E., Clancy, M., Ghalambor, K., Logan, I., Redman, S., et al. (2014). The 2014 Puget Sound Pressures Assessment. Publication \# 2014-04. Tacoma, WA: Puget Sound Partnership.

Micheli, F., Halpern, B. S., Walbridge, S., Ciriaco, S., Ferretti, F., Fraschetti, S., et al. (2013). Cumulative human impacts on Mediterranean and Black Sea Marine Ecosystems: assessing current pressures and opportunities. PLoS ONE 8:e79889. doi: 10.1371/journal.pone.0079889

Moreno, I., del Barrio, I., Lloret, A., and Perez-Puyol, A. (2012). A method for the spatial analysis of anthropogenic pressures in Spanish marine waters. Coast. Eng. Proc. 33, 1-10. doi: 10.9753/icce.v33.management.64

Parravicini, V., Rovere, A., Vassallo, P., Micheli, F., Montefalcone, M., Morri, C., et al. (2011). Understanding relationships between conflicting human uses and coastal ecosystems status: a geospatial modeling approach. Ecol. Indic. 19, 253-263. doi: 10.1016/j.ecolind.2011.07.027

Rodríguez-Rodríguez, D., Sánchez-Espinosa, A., Schröder, C., Abdul Malak, D., and Rodríguez, J. (2015). Cumulative pressures and low protection: a concerning blend for Mediterranean MPAs. Mar. Pollut. Bull. 101, 288-295. doi: 10.1016/j.marpolbul.2015.09.039

Selkoe, K. A., Halpern, B. S., Ebert, C. M., Franklin, E. C., Selig, E. R., Casey, K. S., et al. (2009). A map of human impacts to a "pristine" coral reef ecosystem, the Papahānaumokuākea Marine National Monument. Coral Reefs 28, 635-650. doi: 10.1007/s00338-009-0490-z

Stelzenmuller, V., Lee, J., South, A., and Rogers, S. I. (2010). Quantifying cumulative impacts of human pressures on the marine environment: a geospatial modelling framework. Mar. Ecol. Prog. Ser. 398, 19-32. doi: $10.3354 /$ meps08345

Stock, A. (2016). Open source software for mapping human impacts on marine ecosystems with an additive model. J. Open Res. Softw. 4:e21. doi: 10.5334 /jors. 88

Tillin, H. M., Hull, S. C., and Tyler-Walters, H. (2010). Development of a Sensitivity Matrix (Pressures-MCZ/MPA Features). Report to the Department of Environment, Food and Rural Affairs from ABPMer, Southampton and the Marine Life Information Network (MarLIN) Plymouth: Marine Biological Association of the UK. Defra Contract No. MB0102 Task 3A, Report No. 22.

Tyler-Walters, H., and Jackson, A. (1999). Assessing Seabed Species and Ecosystems Sensitivities. Rationale and User Guide, January 2000 edition. Report to English Nature, Scottish Natural Heritage and the Department of the Environment Transport and the Regions from the Marine Life Information Network (MarLIN). Plymouth, Marine Biological Association of the UK. MarLIN Report No. 4.

Uthicke, S., Fabricius, K., De'ath, G., Negri, A., Warne, M., Smith, R., et al. (2016). Multiple and Cumulative Impacts on the GBR: Assessment of Current Status and Development of Improved Approaches for Management: Final Report Project 1.6. Report to the National Environmental Science Programme, Reef and Rainforest Research Centre Limited, Cairns 144.

van der Wal, J. T., and Tamis, J. E. (2014). Comparing Methods to Approach Cumulative Effects in the North-East Atlantic: CUMULEO Case Study. IMARES Report, Report number C178/13, Wageningen. 
Wiegers, J. K., Feder, H. M., Mortensen, L. S., Shaw, D. G., Wilson, V. J., and Landis, W. G. (1998). A regional multiple-stressor rank-based ecological risk assessment for the Fjord of Port Valdez, Alaska. Hum. Ecol. Risk Assess. 4, 1125-1173. doi: 10.1080/10807039891285036

Wu, Z., Yo, Z., Song, X., Li, Y., Cao, X., and Yuan, Y. (2016). A methodology for assessing and mapping pressure of human activities on coastal region based on stepwise logic decision process and GIS technology. Ocean Coast. Manage. 120, 80-87. doi: 10.1016/j.ocecoaman.2015.11.016

Zacharias, M. A., and Gregr, E. J. (2005). Sensitivity and vulnerability in marine environments: an approach to identifying vulnerable marine areas. Conserv. Biol. 19, 86-97. doi: 10.1111/j.1523-1739.2005.00148.x
Conflict of Interest Statement: The authors declare that the research was conducted in the absence of any commercial or financial relationships that could be construed as a potential conflict of interest.

Copyright (C) 2016 Korpinen and Andersen. This is an open-access article distributed under the terms of the Creative Commons Attribution License (CC BY). The use, distribution or reproduction in other forums is permitted, provided the original author(s) or licensor are credited and that the original publication in this journal is cited, in accordance with accepted academic practice. No use, distribution or reproduction is permitted which does not comply with these terms. 